\title{
SISTEMA DE REMUNERAÇÃO: ESTUDO EM UMA EMPRESA DESENVOLVEDORA DE SOFTWARE
}

\section{RESUMO}

Este estudo tem como propósito investigar o sistema de remuneração e sua contribuição no alcance dos resultados organizacionais na percepção dos funcionários. Para tal foi desenvolvido uma pesquisa exploratória em uma empresa de software localizada no noroeste do estado do Paraná que desenvolve programas de gestão integrada para o gerenciamento de empresas. Para atender aos objetivos da pesquisa os dados foram coletados por meio de entrevistas semi-estruturadas com 06 funcionários, sendo 05 deles programadores e 01 gerente de Recursos Humanos. Dessa maneira foi possível identificar que, apesar dos programadores não terem o pleno conhecimento acerca do sistema de remuneração utilizado pela empresa, há uma percepção positiva deste. Assim eles acreditam que, o sistema de remuneração os incentiva a buscar melhores resultados dentro da empresa, entretanto, foi identificado o desejo dos programadores por mudanças, tanto na política salarial quanto nos benefícios que esta concede. Assim, por meio do estudo, foi possível evidenciar que, é necessário que a empresa conscientize seus funcionários sobre o seu sistema remuneratório, seu significado e do que é constituído para que assim eventuais mudanças sejam percebidas de um modo favorável à organização. Além disso, os programadores manifestaram interesse em benefícios relacionados à saúde e à produtividade.

Palavras-chave: Sistema de remuneração. Salários. Benefícios. Gestão de Pessoas. Indústria de Software.

\section{ABSTRACT}

This study aims to investigate the remuneration system and its contribution to the achievement of organizational outcomes as perceived by employees. For this exploratory research was developed in a software company located in the northwest of the state of Paraná that develops integrated management programs for managing companies. To meet the objectives of the research data were collected through semi-structured interviews with 06 employees, 05 of them being 01 programmers and HR manager. Thus, we found that, despite the developers do not have full knowledge about the compensation system used by the company, there is a positive perception of this. Thus they believe that the pay system encourages them to seek better results within the company, however, the desire of programmers by changes in both wage policy as the benefits it grants was identified. Thus, through the study, it became clear that it is necessary that the company aware their employees about their compensation system, and that its meaning is constituted so that any changes are perceived in a positive way the organization. In addition, developers have expressed interest in health-related benefits and productivity.

Key-words: Compensation System. Wages. Benefits. People Management. Software Industry.

\footnotetext{
${ }^{1}$ Pesquisadora e Bacharel em Administração, Universidade Estadual do Paraná - UNESPAR. (wa-ta-shi-@hotmail.com)
} 


\section{INTRODUÇÃO}

Nos últimos anos, as ações de gestão de pessoas têm sido valorizadas e consideradas como um fator estratégico nas organizações. A percepção dos dirigentes em relação à participação das pessoas no desempenho organizacional destaca a importância do trabalhador no alcance dos objetivos da empresa.

Dessa maneira, as organizações procuram reconhecer seus profissionais por meio de um sistema de remuneração adequado às competências individuais.

A remuneração envolve salários e benefícios e faz parte de um sistema de recompensas que pode contribuir para que a organização se torne uma fonte capaz de atrair e reter funcionários mais talentosos, assim como construir vantagem competitiva frente aos seus concorrentes.

As ferramentas que apoiam essa estratégia de remuneração são os salários e o plano de benefícios, que são considerados formas diretas e indiretas de remuneração, e tem por finalidade promover o reconhecimento e a subsistência, bem como a qualidade de vida do funcionário, seja ela pessoal ou profissional (BOHLANDER; SNELL; SHERMAN, 2003).

Sendo assim, os empregadores esperam que os funcionários tenham maior envolvimento nos processos de trabalho e sejam mais produtivos, contudo é preciso entender quais as ações da gestão de pessoas podem trazer a valorização necessária e requerida pelos trabalhadores, pois o nível de satisfação com o salário e benefícios contribui para o sucesso dessa estratégia.

O problema que orientou essa pesquisa foi: Qual a contribuição efetiva dos programas de remuneração para o alcance de resultados da organização na percepção dos trabalhadores da empresa de software ALFA1?

Seus objetivos específicos foram de descrever o sistema de remuneração da empresa de software ALFA e também de identificar outras formas de remuneração que podem ser incluídas.

Esta pesquisa tem como justificativa a escassez de informações atualizadas a respeito da forma de como é trabalhada e percebida a remuneração no segmento de software, assim como o rápido crescimento das empresas desse setor e a oportunidade de explorar um tema em uma área em desenvolvimento.

Esta pesquisa pode contribuir para novos estudos sobre o tema e levantar informações para a organização analisada para que esta possa fomentar a reflexão e implementação de mudanças, e também para outras organizações que se interessem em estudar os efeitos do sistema de remuneração relatados.

\section{FUNDAMENTAÇÃO TEÓRICA}

\subsection{DA TEORIA DAS RELAÇÕES HUMANAS À GESTÃO ESTRATÉGICA DE PESSOAS}

Introduzindo uma nova concepção para a administração em relação ao ser humano e o seu comportamento no âmbito organizacional, a Teoria das Relações Humanas contestou aspectos criticados nas teorias e modelos apresentados pelas escolas anteriores.

Esse movimento veio em consequência dos estudos procedidos na cidade de Chicago, Estados Unidos, no bairro de Hawthorne em 1927, mas foi a partir de 1929 que suas ideias foram disseminadas e desenvolvidas, trazendo uma nova visão para os trabalhadores dentro

\footnotetext{
1 Nome fictício para preservar a identidade da empresa.
} 
das empresas (MOTA; VASCONCELOS, 2006).

Dessa maneira buscou-se conhecer o comportamento dos trabalhadores, que para Mota e Vasconcelos (2006) não está submetido apenas aos incentivos econômicos, como propagou o modelo Taylorista-Fordista, mas que também é instigado por fatores sociais e emocionais.

No entanto, ainda que tenha modificado a concepção do trabalhador nas organizações, para muitos, a expressão recursos humanos não seria mais adequada para se referir a esse novo indivíduo, dotado de múltiplas dimensões, que não poderia mais ser considerado apenas um mero recurso a ser explorado pela organização, neste contexto, desenvolveu-se o conceito de gestão de pessoas onde o mesmo passou a ser visto com um papel social importante, associado á preocupação com a lucratividade e eficiência (MOTTA; VASCONCELOS, 2006).

Assim começa-se a notar diferentes técnicas de gestão dando forma a perfis gerenciais e sistemas burocráticos mais políticos (MOTTA; VASCONCELOS, 2006). Ainda na visão desses autores (2006) destacam-se alguns papeis importantes exercidos pela gestão de pessoas em sua função administrativa como enfatizar as necessidades e os recursos disponíveis da organização, avaliando a distribuição de funções e como elas estão sendo executadas, remunerando funcionários para incentivá-los a buscarem metas empresariais e treiná-los para melhor conduzirem seus trabalhos.

Neste contexto, Wood Jr. e Picarelli (2004) destacam que, devido às mudanças econômicas, tecnológicas e sociais é importante que as empresas busquem alinhar as práticas de gestão de pessoas às estratégias organizacionais, dando espaço à gestão estratégica de pessoas.

Gestão esta cuja missão é, de acordo com Marras (2005, p. 130), a de se "preocupar mais diretamente com os interesses particulares dos trabalhadores e seus valores culturais próprios, objetivando aliciá-los e engajá-los, cada vez mais, na defesa dos interesses da empresa". Para tal objetivo o auxilio de um bom sistema remuneratório a gestão estratégia de pessoas se torna imprescindível, de acordo com Wood Jr. e Picarelli (2004) a evolução deste sistema, também alinhado as estratégias empresariais favorecem a organização na busca por indivíduos capacitados em um mundo sob constantes mudanças.

\subsection{REMUNERAÇÃO}

A valorização do bem estar e a promoção da qualidade de vida do funcionário vêm ganhando espaço nos processos decisórios das organizações. Nesse sentido, destacase o papel da remuneração, que pode ser considerada como uma forma de proporcionar estabilidade para o trabalhador, bem como, potencializar desempenhos melhores e reduzir o turnover da empresa, constituindo uma das ações da Gestão de Pessoas. Segundo Lobos (1979), a remuneração inclui todos os tipos de recompensas e pagamentos que a empresa oferece ao empregado, em consequência do desempenho do seu trabalho, podendo ser direta ou indireta.

A remuneração direta é descrita por Bohlander et al (2003) como aquela na qual estão inclusos o salário, as bonificações, os incentivos e as comissões, enquanto que, a remuneração indireta é aquela que inclui os benefícios oferecidos pela empresa, as recompensas não financeiras, programas de reconhecimento dentre outros.

Segundo Marras (2009), a remuneração é responsabilidade da Gestão de Pessoas, e é também umas das funções mais importantes de seus subsistemas o setor de cargos e salários. Dessa maneira, de acordo com Milkovich e Boudreau (2009) a remuneração se torna uma ferramenta importante para a organização, tanto na atração e retenção de empregados, mas também como um fator que influencia em sua satisfação e desempenho, e deve ser administrada de maneira cuidadosa, pois constitui um dos principais custos empresariais. 
Na visão dos mesmos autores (2009) um bom sistema de remuneração é aquele que equivale ou supera o oferecido pela concorrência, sendo perceptível para os funcionários, sejam eles atuais ou potenciais.

Assim, segundo Bohlander et al (2003) os benefícios de um sistema remuneratório também podem estar ligados a funções especificas da gestão de pessoas, como exemplo nos processos de recrutamento e de seleção de pessoal.

No recrutamento, os salários e benefícios oferecidos pela empresa têm influência na demanda de candidatos, podendo aumentar ou limitar a quantidade dos mesmos para determinada vaga, já na seleção se houver um alto nível de salários e benefícios oferecidos pela empresa criam-se maior disponibilidade de candidatos, o que favorece os níveis de padrões de seleção, assim a empresa pode optar por funcionários mais capacitados e qualificados (BOHLANDER et al, 2003).

Portanto, para que a empresa possa constituir uma fonte estratégica de atração e retenção, através de sua remuneração, na visão de Aquino (1980), é necessário que, a percepção do dirigente em relação à remuneração e sua estrutura salarial, compreenda que, para o trabalhador, o salário não tem significado apenas por seu valor econômico, mas que também existem fatores internos e externos a serem ponderados. Logo, podem ser desperdiçados tempo e recursos, se a empresa, ao adotar outros estímulos remuneratórios, não proporcionar, para seus trabalhadores, políticas salariais sadias e consistentes.

\subsubsection{Salário}

A remuneração direta, mais conhecida como salário, segundo Marras (2009), é um termo que pode ser definido de muitas formas, dependendo de como o mesmo é aplicado e apresentado ao empregador.

Segundo Lobos (1979) o salário é a forma restrita de recompensar o indivíduo pelo exercício de cumprir as suas obrigações e compromissos, relativos ao seu cargo, convencionado em seu contrato de trabalho. Ainda na visão do autor (1979), atrair indivíduos capacitados, que agreguem valor e força de trabalho para a organização, através do mercado de trabalho externo, é uma questão que depende de fatores como o nível de competitividade relacionado aos salários pagos pela empresa na indústria, a região e a formulação de políticas salariais que se posicionem frente às outras empresas que fazem parte do mesmo mercado.

É dessa forma que o salário está associado à gestão estratégica de pessoas, pois, esta, segundo Wood Jr. e Picarelli (2004, p. 76) "pressupõe que pessoas não são recursos perecíveis, porém ativos valiosos, que devem ser desenvolvidos e que são os principais responsáveis para desenvolver os negócios".

Assim, para o trabalhador, o salário excede as características de uma variável econômica, ele representa uma relação diferente e está associado à sua situação social e econômica bem como o seu status perante a sociedade, dessa maneira o indivíduo tende a buscar melhores condições salariais, no intuito de suprir suas necessidades de sobrevivência e de consumo (AQUINO, 1980).

Existem dois fatores que exercem influência sobre os salários atribuídos aos funcionários segundo Bohlander et al (2003), são os fatores internos, como: políticas de remuneração adotadas pela empresa, o valor atribuído ao trabalho, o valor do funcionário no exercício de seu cargo e a capacidade de pagar do empregador. $E$ os fatores externos que são: o custo de vida, as faixas salariais, as condições do mercado de trabalho e os requisitos legais de negociação coletiva.

Dessa maneira, as empresas buscam fontes de referência para a decisão salarial. Uma 
das maneiras possíveis de se escolher uma determinada política salarial, segundo Barbieri (2012, p. 39) "é definir se a empresa quer pagar um salário-base conservador e um salário total mais agressivo ou um salário-base mais agressivo e um salário total mais conservador".

Existe também a chamada pesquisa salarial que, de acordo com Milkovich e Boudreau (2009, p. 388), "levantam os valores de remuneração para funções específicas praticadas pelos concorrentes mais relevantes". Bohlander et al (2003) afirmam que, a pesquisa de salários faz com que a empresa se encontre em igualdade salarial em relação aos concorrentes, ou seja, permite que a mesma tenha equidade externa.

Assim, as pesquisas salariais não servem apenas para coletar dados, e obter referencial sobre os salários pagos pelos concorrentes, mas também sobre os benefícios e os sistemas remuneratórios que os mesmos oferecem, tendo em vista que atualmente praticamente todas as empresas buscam auxiliar o salário pago aos seus empregados através de benefícios oferecidos como forma de remuneração indireta, alguns desses benefícios são exigidos por lei considerados como parte da remuneração total (BOHLANDER et al, 2003).

\subsubsection{Benefícios}

Considerados como formas de compensação indireta os benefícios compõem o sistema de remuneração, que segundo Milkovich e Boudreau (2009) incluem gratificações alheias ao trabalho como, planos privados de seguros, serviços aos empregados e renda de aposentadoria.

De acordo com Marras (2009) os programas de benefícios podem garantir um baixo índice de rotatividade, contribuir na qualidade de vida dos empregados e tornar a organização mais competitiva no mercado de trabalho.

Ainda na visão do autor (2009) eles se subdividem em benefícios compulsórios e espontâneos. Os compulsórios são aqueles que são oferecidos para o cumprimento de leis trabalhistas, como exemplo: auxilio doença, $13^{\circ}$ salário, férias, salário maternidade entre outros. Em relação a esse tipo de benefícios Bohlander et al (2003) afirma que os mesmos não são mais vistos somente como uma vantagem proposta pelo empregador, e sim como uma área da legislação trabalhista constituída por direitos exigidos por todos os funcionários.

Os benefícios espontâneos, de acordo com Marras (2009), são oferecidos aos empregados pela empresa por decisão própria, os mais comuns são restaurantes, seguros de vida, assistência médica, festas, transporte entre outros, esses benefícios também podem ser oferecidos por acordos e convenções trabalhistas entre empresas e sindicatos.

Os efeitos dos benefícios não são muito bem documentados pelos candidatos na hora de aceitar o cargo, nem mesmo após o contrato. Os benefícios apenas podem ter sobre estes candidatos um efeito indireto sobre o seu desempenho (MILKOVICH; BOUDREAU, 2009).

Na visão dos mesmos autores (2009), os efeitos dos benefícios sobre o comportamento do empregado são complexos e difíceis de serem documentados, enquanto que calcular os seus efeitos sobre os custos empresariais é uma tarefa mais fácil para a organização. Isso significa que, planos adequados de benefícios podem influenciar a satisfação dos trabalhadores e proporcionar um ambiente de trabalho mais igualitário.

Assim, as empresas, ao optarem por determinados tipos de benefícios, precisam estar cientes de alguns cuidados importantes, como o de identificar os tipos de benefícios que mais correspondam às necessidades dos trabalhadores, e o de fazer com que os mesmos ao receber este beneficio possam se sentir valorizados por terem participado de algo dentro da empresa (AQUINO, 1980). Alguns dos benefícios mais utilizados pelas empresas, segundo o mesmo (1980), são os de assistência médica, que constituem um dos benefícios de maior 
aceitação entre os trabalhadores, os de alimentação e os de transporte.

Os benefícios, evidentemente, têm grande importância como partes do sistema de remuneração, também constituem um grande auxilio quando se fala em Gestão Estratégica de Pessoas, pois, a mesma, é responsável por preparar e organizar políticas que promovam mudanças favoráveis nos resultados da empresa, tendo em vista que a intenção da Gestão Estratégica é atrair capital humano qualificado e utilizá-lo como um diferencial (MARRAS, 2009).

\section{MÉTODOS}

O trabalho em questão trata-se de uma pesquisa de natureza qualitativa, que, segundo Richardson (2010, p. 79), "justifica-se, sobretudo, por ser uma forma adequada para entender a natureza de um fenômeno social". Quanto a seus objetivos, caracteriza-se como pesquisa de caráter exploratório, devido à escassez de estudos atualizados sobre remuneração em empresas de software. A pesquisa de caráter exploratório segundo Richardson (2010) é aquela que investiga um tema ou fenômeno que tenha pouco ou nenhum estudo, para procurar, posteriormente, explicações de fatos ou consequências.

Por se tratar de uma pesquisa qualitativa, os dados foram coletados por meio de entrevistas semi-estruturadas, que foram realizadas por meio de um roteiro com questões formuladas antecipadamente, no intuito de orientar a entrevista e levantar os temas necessários para o estudo. As entrevistas foram realizadas com local e horário previamente agendado, sendo entrevistados ao todo 06 funcionários, entre eles 05 são programadores e 01 gerente de Recursos Humanos, a fim de avaliar, com o auxilio do aporte teórico, questões relacionadas à percepção que estes possuem sobre modelo de remuneração oferecido pela empresa de software.

Também foi usada a análise documental através de documentos que foram concedidos pela empresa, como manual de cargos e salários, o regulamento interno da empresa e o formulário de avaliação de desempenho.

Quanto à análise de dados, foi utilizado o método de análise de conteúdo, caracterizado como um conjunto de instrumentos metodológicos que se encontram em constante aprimoramento e podem ser aplicados em discursos variados que possibilitam a descrição e a interpretação, através da teoria, do conteúdo das mensagens (BARDIN, 1977).

\section{APRESENTAÇÃO E ANÁLISE DOS RESULTADOS \\ 4.1. CARACTERIZAÇÃO DA EMPRESA}

O presente estudo ocorreu em uma empresa que atua no desenvolvimento de softwares e atualmente possui 40 funcionários, sendo 10 deles programadores, 04 assistentes administrativos, 04 funcionários com cargos de chefia, os demais atuam nas áreas de serviços gerais, e atendimento. Existem duas unidades da empresa, contudo, o trabalho concentrou-se apenas em uma delas, localizada em um município de aproximadamente 90 mil habitantes no noroeste do estado do Paraná. Para o desenvolvimento deste trabalho, bem como para a exposição de informações, o nome da empresa foi preservado, sendo esta identificada como ALFA.

A empresa de software ALFA surgiu em meados de 2000, através da fusão de duas outras empresas que também atuavam no setor de software, inicialmente, esta desenvolvia e fornecia sistemas integrados de Gestão (ERP) 2 para empresas de diversos seguimentos como varejo e agroindústria.

\footnotetext{
${ }^{2}$ Enterprise Resource Planning (Planejamento de Recursos Empresariais).
} 
Atualmente a empresa ALFA, além de desenvolver softwares de gestão também desenvolve diversos aplicativos ligados à Nota Fiscal Eletrônica (NF-e), dentre eles o primeiro aplicativo open source (código-livre e gratuito) para a transmissão de arquivos XML3 da NFe, que atraiu rapidamente a atenção do mercado sendo adotado por diversas empresas de software no país.

Dessa maneira, através da tecnologia da informação, a empresa ALFA desenvolve programas de computadores para o gerenciamento de empresas e para o controle de todos os setores organizacionais, desde a produção, compra, comércio, venda contabilidade até relatórios gerenciais entre outros, com o intuito de organizar as informações e facilitar as ações empresariais.

\subsection{ENTREVISTA COM PROGRAMADORES E GERENTE DE RECUR- SOS HUMANOS DA EMPRESA DE SOFTWARE ALFA}

A partir dos depoimentos obtidos dos funcionários que atuam na área de desenvolvimento de software, constatou-se que quatro possuem entre 18 e 23 anos e dois possuem entre 24 e 29 anos com idade média de aproximadamente 23 anos, o tempo médio de empresa entre esses trabalhadores é de 04 anos, o entrevistado com menor tempo de empresa possui 01 ano e o com maior 07 anos, quanto à formação um dos entrevistados não possui formação superior, três deles cursam Sistema de informação, e dois são graduados um em Análise e desenvolvimento de sistemas e o gerente de Recursos Humanos é tecnólogo em Recursos Humanos.

Assim, através da entrevista foi possível notar, em um primeiro momento, que os programadores quando questionados sobre a forma de remunerar da empresa apresentaram pouca compreensão sobre o significado de remuneração, havendo a necessidade de uma breve explicação para que pudessem descrever ao seu entendimento como é o sistema remuneratório oferecido pela organização em que atuam. Portanto, pode-se considerar que os entrevistados possuem pouca informação sobre o mesmo, o depoimento do programador III comprova isso "Sim, é a meritocracia, uma avaliação $360^{\circ}$ graus, onde cada avaliador e cada questão têm um peso, cada um avalia o próprio companheiro para determinar a faixa salarial". Da mesma forma o programador IV relata que "Em termos, bom eu não procuro muito saber e isso é uma falha minha, pois a transparência aqui é clara, mas de certa forma eu não sei muito, mas é por falta de interesse mesmo".

A falta de compreensão, por parte do funcionário, em relação à sua remuneração, pode desencadear uma série de problemas para organização, tais como, insatisfação no ambiente de trabalho, considerar o salário oferecido insuficiente, e, consequentemente, queda de qualidade no trabalho e a não percepção de eventuais incentivos e benefícios. Assim, ao ser questionado sobre como funciona o sistema de remuneração oferecido pela empresa, o gestor demonstra ter consciência desta situação e relata providências de mudanças:

Temos o salário e os benefícios que normalmente são a média do mercado e também fizemos uma pesquisa onde a gente define a média de mercado ou acompanhamos isso, e se tiver muita distorção eu já trago para dentro do nosso plano de cargos e salários. Também existe um procedimento e muito dos funcionários leram, mas com o passar do tempo eles acabam esquecendo e desconhecendo, então eu estou refazendo o plano de cargos e salários justamente para que eles tenham conhecimento (Relato entrevista - gerente de RH).

O Plano de cargos e salário do qual o gestor refere-se, foi fornecido para a análise desta pesquisa bem como o regulamento interno da empresa e o formulário de avaliação de desempenho, assim foi possível identificar através desses documentos que desempenhos

\footnotetext{
${ }^{3}$ Arquivos de Nota Fiscal Eletrônica.
} 
satisfatórios a empresa por parte dos funcionários em seu cargo, possibilita o seu crescimento dentro da mesma, seja ele vertical ou horizontal. Desse modo, apresentar esses documentos e procedimentos aos funcionários, dando a eles acesso aberto a essas informações pode ser uma das maneiras de engajá-los em seu processo remuneratório, que, segundo Milkovich e Boudreau (2009), tem um papel importante para a organização, tanto na atração e retenção de empregados, mas também como um fator que influência em sua satisfação e desempenho.

Assim é possível notar que, mesmo desconhecendo alguns aspectos remuneratórios, os programadores quando questionados se a remuneração oferecida possui um papel importante para a sua permanência dentro da empresa, expressaram que esta exerce influência sobre a sua estadia na organização, assim como relata o programador IV:

Sim, o vale-transporte é um exemplo, eu não uso, mas tem funcionários aqui na empresa que precisam muito, pois moram longe e não é todo mundo que tem carro. O vale alimentação também e por mais que seja $R \$ 50,00$ ou $R \$ 100,00$ é um alivio, pois com $R \$ 100,00$ você faz muitas coisas. E o salário em si é justo, pois tem um plano que te dá mais empenho que seria a participação nos resultados, então você tenta conseguir mais, pois em um cargo maior você consegue um maior salário e assim se empenham mais para crescer na empresa (Relato de entrevista - programador IV).

É comum funcionários optarem porempresas que recompensem melhor seus trabalhadores por meio de salários e benefícios, das quais podem obter crescimento e valorização no exercício de suas tarefas, de acordo com Milkovich e Boudreau (2009), para que um sistema de remuneração seja considerado bom é necessário que na percepção dos funcionários seja equivalente ou que supere o da concorrência. Questionados sobre esses aspectos foi possível compreender que na percepção dos programadores a remuneração que recebem equivale e até supera a dos três concorrentes existentes na cidade, assim o programador $V$ relata que "Supera, pois entre as empresas de desenvolvimento das quais já cheguei a ter conhecimento à faixa salarial é menos do que a que ganhamos aqui". Neste sentido o programador IV reforça dizendo que "Eu como estudante e não formado, aqui nessa cidade ainda não consegui achar emprego melhor na minha área, acredito que supera o da concorrência".

Do mesmo modo, questionado sobre esses fatores, o gestor demonstrou acreditar que o sistema utilizado pela empresa se caracteriza como um diferencial competitivo, superando assim o da concorrência, conforme foi relatado em seu depoimento "Eu vejo que o meu salário é maior que o da concorrência, então eu consigo chegar até a diretoria e falar que eu tenho um salário mais alto que a média do mercado e também tenho pessoas mais produtivas".

O gestor de Recursos Humanos explica, ainda, que está entre os objetivos da empresa diferenciar seu modelo de remuneração das demais organizações do ramo, no intuito de obter uma participação mais ativa de seus funcionários e uma melhor atuação em suas funções, é nesse ponto de vista que um bom sistema remuneratório, alinhado a gestão estratégica de pessoas, se destaca. Como descrito por Marras (2005, p. 130) busca se "preocupar mais diretamente com os interesses particulares dos trabalhadores e seus valores culturais próprios, objetivando aliciá-los e engajá-los, cada vez mais nos interesses da empresa".

Assim, questionados sobre o modelo de remuneração utilizado pela empresa e se este os torna mais próximos dos objetivos e metas organizacionais, foi possível notar que na percepção dos programadores, este sistema tem os incitado a buscar maior desempenho e produtividade, conforme o relato do programador I "Sim, sem dúvidas, pois o benefício baseado no trabalho e no desempenho estimula muito mais". Do mesmo modo, o programador $\checkmark$ afirma que "Acredito que sim, também tem a questão da participação nos resultados que incentiva bastante". E segundo o programador II "o Salário e a participação nos resultados é assim que se fala? Vale alimentação e esses benefícios? Sim é bem estimulante".

Neste sentindo, é possível notar no depoimento dos programadores a contribuição que a 
participação nos resultados (PRs) tem obtido sobre o modelo de remuneração da empresa, deste modo o gestor esclarece que "Temos duas PRs no ano são dois salários, metade vinculada ao alcance de metas de vendas da empresa em geral e a outra metade são do alcance das metas do setor, assim se o setor alcança as metas de produção eles recebem metade de um salário.

Questionados quanto à política salarial adotada pela empresa ALFA, na percepção dos programadores pode ser considerada justa ou regular, porém como explica o depoimento do programador I e do gerente de RH esta passa por um processo de mudanças:

Estamos redefinindo a política salarial, porque queremos criar algo ou um sistema mais justo para definir a remuneração de acordo com a produtividade, estamos trabalhando agora em uma mudança, temos o nosso setor fazemos reuniões e discutimos sobre isso. A nossa ideia agora é que de acordo com a produtividade vamos definir o bônus que o funcionário irá receber (Relato de entrevista - programador I).

O pessoal de programação acredita que o plano de cargos e salários não atende ao que eles querem, pois eles têm mais ânsia salarial. Talvez vá mudar alguma coisa na remuneração, vai ser produção igual ao vendedor que seria no caso a comissão, mas estamos estudando ainda (Relato de entrevista - gerente de RH).

De acordo com Aquino (1980), para o trabalhador, o salário excede características de uma variável econômica, ele representa uma relação diferente e está associado a sua situação social e econômica bem como o seu status perante a sociedade, dessa maneira o indivíduo tende a buscar melhores condições salariais, no intuito de suprir suas necessidades de sobrevivência e de consumo.

Assim, torna-se de extrema importância, tanto para a empresa quanto para o funcionário, que o salário oferecido seja compatível ao seu cargo e às suas funções, caso contrário o trabalhador poderá se sentir insatisfeito e procurar outras opções de trabalho em detrimento do salário pago a ele que não está de acordo com sua ocupação e até mesmo com suas aptidões. Questionados sobre esses aspectos os programadores da empresa ALFA demonstram acreditar que o salário oferecido está de acordo com o cargo que estes exercem e com o que o mercado estipula, entretanto com base no que foi dito anteriormente é evidente o desejo dos mesmos de mudança em relação à política salarial da empresa.

Porém, um sistema de remuneração não é constituído apenas pelo salário, também existem os benefícios que podem ser considerados como uma maneira indireta de gratificar os empregados (MILKOVICH; BOUDREAU, 2009), dessa maneira através da análise dos documentos fornecidos pela empresa, foi possível identificar que seus benefícios constituemse em: vale transporte e vale alimentação, horários flexíveis, ajuda com $50 \%$ em cursos de pós-graduação e a participação nos resultados.

Estes benefícios, para os programadores entrevistados, foram considerados como justos, porém eles expressam interesse em alguma forma de benefício mensal relacionado à participação nos resultados conforme o depoimento a seguir:

Falando sobre os benefícios que recebemos até agora, isso quando falo que está havendo algumas mudanças, pois o benefício semestral que só recebemos quando atendemos as metas semestrais, por ser em longo prazo não estimula tanto então queremos que o tempo para recebê-lo seja menor, desse modo eu acho interessante (Relato de entrevista - programador I).

Também foi identificada uma demanda, por parte dos funcionários, relativa a benefícios voltados à saúde, como os planos de saúde, os quais, segundo Aquino (1980), estão entre os benefícios de maior aceitação entre os trabalhadores, juntamente com o de alimentação e o de transporte. Questionado sobre esses benefícios o Gestor explica que: 
O pessoal do setor de programação acredita que a PR sendo semestral é muito ruim, por isso eles querem que seja mensal. Então eu vou ver se pela lei eu consigo transformar em mensal. Quanto ao plano de saúde, existe uma ideia, mas não no momento, pois aqui na cidade este benefício não é cultural (Relato de entrevista - gerente de RH).

Observa-se neste ponto que quando interrogado a respeito de benefícios ligados a saúde, o gerente de $\mathrm{RH}$ alegou como justificativa o aspecto cultural da região como barreira, porém existem várias empresas, de diferentes setores na região, que disponibilizam este tipo de benefício.

Já em relação a questão dos benefícios de maior aceitação entre os programadores, está o vale alimentação e a participação nos resultados, entretanto o beneficio de ajuda com $50 \%$ em pós-graduação não é percebido como tal, justificada principalmente pelo desconhecimento do mesmos, uma vez que a maioria dos entrevistados se encontram em formação nível de graduação e, no momento, não fazem uso de tal auxílio.

Além disso, pode ser identificado que os programadores passaram a conhecer alguns dos benefícios, oferecidos pela empresa, somente a partir da entrevista de emprego ou mesmo após a contratação. Tendo em vista que a análise cognitiva dos funcionários sobre os benefícios tende a ser equivalente a análise do salário, é importante para empresa que seus funcionários tenham claro conhecimento sobre os seus benefícios, assim como o mercado de trabalho, pois da mesma forma que ao serem concedidos podem melhorar a retenção, eles também aumentam a atração.

Desse modo, Marras (2009) reforça que o programa de benefícios pode garantir um baixo índice de rotatividade, contribui com a melhoria da qualidade de vida dos empregados e torna a organização mais competitiva no mercado de trabalho.

Após a pesquisa, também foi possível identificar as modificações e avanços requeridos pelos funcionários quando questionados sobre melhorias que gostariam de sugerir, assim, os entrevistados expressaram acreditar que certas mudanças não se encaixam com a realidade da empresa, pelo fato desta ainda estar em crescimento e, no momento, ser considerada pequena, contudo acreditam que, dentro do possível, alguns aspectos relacionados aos benefícios e ao modelo remuneratório da empresa poderiam ser melhorados, tais como a política salarial, a inclusão de benefícios ligados à saúde e ter uma participação maior nos resultados da empresa.

\section{CONSIDERAÇÕES FINAIS}

De modo geral, os resultados levantados neste estudo demonstraram que, apesar dos funcionários da empresa de software ALFA não apresentarem pleno conhecimento sobre o tema remuneração, pode-se observar que, na visão deles, há uma percepção positiva em relação às estratégias remuneratórias utilizadas pela empresa, e que estas tem contribuído para o alcance de bons resultados, isso se deve ao fato de que, para a maioria dos entrevistados, o salário oferecido e os benefícios, em destaque a participação nos resultados, tem sido fonte de estímulo para o alcance das metas empresariais e de uma maior produtividade. Entretanto, este sistema, atualmente, tem passado por processos de mudanças, em resposta às exigências dos trabalhadores.

Assim, conforme proposto neste estudo também houve a descrição do sistema remuneratório através da análise dos documentos e da entrevista, que possibilitou constatar que este sistema utilizado pela empresa é constituído por salários e benefícios baseados na média do mercado e que, dentro de suas limitações, esta vem buscando consolidá-lo por meio de algumas mudanças, a fim de obter um nível maior de satisfação e rendimento de seus funcionários. 
Contudo, é importante conscientizar a empresa de que seus funcionários devem ter claro entendimento e conhecimento sobre os programas de remuneração, de seu significado e de sua composição, pois, eventuais movimentos de melhora realizados poderão não ser satisfatoriamente percebidos. Sendo assim, para que estes possam entender como esse processo funciona, podem ser implantadas algumas ações como, disponibilizar materiais informativos, promover reuniões para apresentar, discutir e observar a percepção do funcionário em relação à remuneração e, como forma de minimização de custos, pode ser utilizado o e-mail como canal informativo. Desse modo, o sistema de remuneração pode se tornar mais claro, para os funcionários, e, de certa forma, mais estimulante.

Também foram identificadas através dos resultados obtidos pela análise, outras formas de remuneração como sugestão que podem ser incluídas no sistema atual da empresa, desse modo é aconselhável que a empresa faça um estudo mais aprofundado sobre a possível implantação de um benefício ligado à saúde, já que pode ser identificado como algo relevante e de utilidade para os funcionários, diferentemente do benefício relacionado à pósgraduação que não é percebido como tal por não ter utilidade no momento para a maioria dos funcionários que ainda não concluíram a graduação. Sugere-se ainda um estudo a respeito da participação nos resultados e de possíveis gratificações baseadas em metas empresariais e de produtividade que possam ser concedidas em curto prazo, preferencialmente de forma mensal.

\section{REFERÊNCIAS}

AQUINO, Cleber Pinheiro de. Administração de Recursos Humanos: Uma introdução. São Paulo: Atlas, 1980.

BARBIERI, Ugo Franco. Gestão de Pessoas nas Organizações: Práticas atuais sobre o RH estratégico. São Paulo: Atlas, 2012.

BARDIN, Lawrence. Análise de Conteúdo. São Paulo: Edições 70, 1977.

BOHLANDER, G.; SNELL, S.; SHERMAN, A. Administração de Recursos Humanos. São Paulo: Cengage Learning, 2003.

LOBOS, Júlio A. Administração de Recursos Humanos. São Paulo: Atlas, 1979.

MARRAS, Jean Pierre. Administração de Recursos Humanos: Do operacional ao estratégico. 13. ed. São Paulo: Saraiva, 2009.

MARRAS, Jean Pierre. Gestão de Pessoas: Em empresas inovadoras. São Paulo: Futura, 2005.

MILKOVICH, George T.; BOUDREAU, John W. Administração de Recursos Humanos. 8. ed. São Paulo: Atlas, 2009.

MOTTA, F.C.P; VASCONCELOS, I.F.G. Teoria Geral da Administração. 3. ed. São Paulo: Cengage Learning, 2006.

RICHARDSON, R. J. Pesquisa social: métodos e técnicas. 3. ed. São Paulo: Atlas, 2010.

WOOD JR, Thomaz; PICARELLI FILHO, Vicente. Remuneração e Carreira por Habilidades e por Competências: Preparando a organização para a era das empresas de conhecimento intensivo. 3. ed. São Paulo: Atlas, 2004. 